\title{
Social Skills Acquisition Among Engineering and Management Research Scholars
}

\author{
S. Jayalakshmi, P. Balaji
}

\begin{abstract}
This study was conducted to explore the determinants of social skills acquisition among research scholars. The empirical research design was adopted by employing questionnaire method to gather perception and responses from respondents. The primary data collected were subjected to analysis using PSPP software and the statistical tools such as, percentage analysis, descriptive statistics, Independent sample t test and Analysis of Variance has been applied to draw meaningful findings. Four dominant factors have been extracted out of 21 social skills variables of which the team building factor is the most dominant factor followed by responsibility factor, peer relations factor and motivation factor. There is a significant difference between marital status, medium of instruction, course work completion and research stage of research scholars with respect to social skills. Further, the research proves that research scholars participated in the survey have higher perception towards all the four components of social skills acquisition. The researchers are suggested to develop and enrich their social skills and self-competence in order to complete their research within the stipulated time.
\end{abstract}

Keywords : Social Skills Acquisition, Research Scholars, Motivation, Team Building and Responsibility.

\section{INTRODUCTION}

$\mathrm{T}_{\mathrm{w}}$ wenty first century was witnessing rapid change and complexion in managing the human forces towards the excellence in academic and industry environment across the globe. Especially, in higher education sector it is very complex to make the students more employable (Andrews, \& Higson, 2008) and adoptable in today's competitive environment. The professional bodies, Government and other national committees should focus on the design of appropriate education system with career development opportunities (National Research Council 1996; Garet,\& et al., 2001). Indian higher education system subjected to lot of radical changes and structural reformation as par as policies and standard is concern (Ball, 2017; Muralidharan, 2013; Trowler, 2008; Jayaram, 2004). The Government is looking for those institutions with potential for 'Institute of Eminence' in order to cope up with established and high ranked foreign university. These changes will make the

Revised Manuscript Received on December 05, 2019.

* Correspondence Author

Dr. S. Jayalakshmi*, Assistant Professor, Department of Commerce, Chellammal Women's College, Guindy, Chennai - 600 032, Tamil Nadu, India

Dr. P. Balaji, Assistant Professor, P.G and Research Department of Commerce, Guru Nanak College (Autonomous), Chennai - 600 042, Tamil Nadu - India higher education more versatile and challenging for the purpose of economic transmission. These changes should ensure the standard in quality of higher education offered in India (Agarwal, 2006; Singh, J. D, 2011; Kumar, S., \& Dash, 2011). As it was witnessed in many other nations that modernisation of higher education is not only a matter of policies, strategies, organisations and structures but also a question of individual behaviour and attitudes. On the other hand, the universities are becoming the manufacturing units to produce a greater number of Ph.D.'s in the recent years and surprisingly, those Ph.D. holders are showing positive intend towards other non-teaching Government jobs in the recent years (Zusman, 2005)

In the recent years, higher education institutions are lacking in teachers in both quantitative and qualitative aspect of results (Boud, \& Falchikov, 1989; Trigwell, \& Prosser, 1991; Biggs, 2001). Higher education institutions are in deficit of appropriate human resources for the effective function in the long run. In this study an attempt has to be made to investigate the social skills acquisition, ethicality in research and environment of higher education in Tamil Nadu was tend be explored through the investigation among research scholars in higher education institutions from the state of Tamil Nadu.

\section{REVIEW OF LITERATURE}

Poulou and Bassett et.al (2018) critically investigated the emotional intelligence and social emotion learning skills of US and Greek preschool students with respect to the perception of teachers. The authors examined the teachers' perception on the application and implication of emotional intelligence in the social skills for behavioural and emotional transformation among the student's community. The authors found that emotional intelligence have significant influence and relationship with ability and development of proper emotion management.

Massoumeh Zandi (2012) conducted a study to examine the role of emotional intelligence in French language learning and academic success of the female students. The authors have adapted the questionnaire method to collect data from 239 femalestudents. The authors have been found the function of the emotional intelligence learning French and the achievement of the female students. Findings revealed that there existed a significant correlation between subjects' achievement and stress management, adaptability, reading skill and stress management, general mood and adaptability, speaking

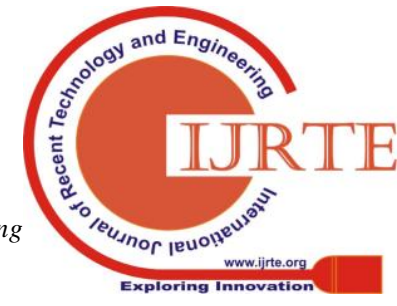




\section{Social Skills Acquisition Among Engineering and Management Research Scholars}

skill and emotional intelligence quotient and intrapersonal intelligence and stress management.

Massoumeh Zandi (2012) discussed the role of emotional intelligence in French language learning and academic success of the male students. The authors have been examined to analyze the relationship between the emotional intelligence and educational achievement of the male students in learning French. The authors adapted questionnaire method to collect information on emotional intelligence from 250 male students The authors found that there is a significant correlation between average grade point and stress management.

Annamaria Di Fabio and Maureen Kenny (2012) explored the emotional intelligence perceived social support among Italian high school students. The researcher has been examined the relationship of emotional intelligence as assessed by personality and self -report measures with perceived levels of social support. The researcher collected primary information from 390 students Tuscan school system participants in the study. Finally, the authors have revealed that actual skill in emotional intelligence is relevant and related to perceived social and support, self-perception of emotional intelligence skills appear to matter as much and perhaps more than emotional intelligence as assessed through performance measures.

Madhavan \& Poonsook (2016) measured the relationship between emotional intelligence and academic achievement of business students. The author has been examined to measure the relationship between and academic achievement of final year business student studying in various streams. The authors have adapted the questionnaire and the data were collected from the students and population of the study 618 student of year 1 to 3 years BBA in various streams, simple random sample and study attempted to target the 618 respondents and they received 349 valid responses the that emotional intelligence screening test. The study revealed that emotional intelligence and academic performance have higher correlation to each other.

Charles and Stefanie Brandenburg (2013) discussed the emotional intelligence and academic performance of engineering students. The authors have been examined the paper is to attempt to correlation emotional intelligence with the academic performance of civil engineering students. The authors have been adapted the research included the participation of three classes in the civil engineering department at Clemson university and two classes in the civil and environment engineering department at the citadel. Participants were primarily junior and senior at both institutions, while the Clemson group did include 24 graduate students. Finally, there is a relationship between GPR and EI. In addition, the participants in this research have anonymity and are guaranteed that their responses are not part of their individuals' academic evaluations, the respondents' ability to answer honesty.

\section{STATEMENT OF THE PROBLEM}

There has been a concern for stake holders of higher education on factors contributing to research performance of the students in institutions of Higher Learning. Cognitive intelligence and emotional intelligence enable positive development in academic and quality of life of the students. Higher skills acquisition gives added advantage to the scholars in their research contribution. Therefore, this study attempts to identify the social skills acquisition of $\mathrm{Ph} . \mathrm{D}$. students registered in the Anna University.

\section{OBJECTIVES OF THE STUDY}

1. To study the demographic and research profile of the research scholars.

2. To measure and understand underlying dimensions of Social Skills Acquisition (SSA) variables.

3. To examine significant difference between various demographic and educational profile of the research scholars with respect to Level of social skills acquisition.

\section{RESEARCH METHODOLOGY}

Non- Random Purposive Sampling was adopted for collecting primary data and 200 questionnaires were issued and the respondents were given sufficient time for filling the questionnaire. 170 of the issued questionnaires were received back from the respondents. On scrutiny of these 15 of them were found to be incomplete and 15 were not suitable for the study due to extreme values. Finally, the remaining 140 samples was taken for the study.

\section{RESULTS AND DISCUSSION}

\section{A. Demographic and Research Profile of the Respondents}

Percentage analysis and descriptive statistics has been applied to understand the demographic and educational profiles of the research scholars. The results are tabulated and presented in the Table 1.

Table 1: Frequency Table of Demographic Characteristics

\begin{tabular}{|cl}
\hline Demographic and Research Profile $(\mathbf{N}=\mathbf{1 4 0})$ & $\begin{array}{l}\text { Frequency } \\
\text { (Percentage) }\end{array}$ \\
\hline Gender & $\mathbf{7 4}(\mathbf{5 2 . 9 )}$ \\
Male & $66(47.1)$ \\
Female & \\
Marital Status & $39(27.9)$ \\
Married & $101(\mathbf{7 2 . 1 )}$ \\
Unmarried & \\
Medium of Language in School & $21(15.0)$ \\
Tamil & $115(82.1)$ \\
English & $4(2.9)$ \\
Others & \\
\hline Coursework Completion & $\mathbf{5 1}(36.4)$ \\
Yes & $42(30.0)$ \\
No & $47(33.6)$ \\
\hline Not Applicable & \\
\hline
\end{tabular}

Nature of Researcher 
Stipendiary

38 (27.1)

Non - Stipendiary

102 (72.9)

Researcher Stage

Title Selection

19 (13.6)

Review

34 (24.3)

Questionnaire Construction

22 (15.7)

Pilot Study

$10(7.1)$

Data Collection

24 (17.1)

Synopsis

22 (15.7)

Dissertation / Thesis Submission

Descriptive Statistics

$\begin{array}{llll}\text { Minimum } & \text { Maximum } & \text { Mean } & \text { Std. Deviation } \\ 22 & 49 & 27.84 & 4.945\end{array}$

Age

Table 1 indicates that majority of the respondents are males $(52.9 \%)$, unmarried $(72.1 \%)$, non-stipendiary $(72.9 \%)$ research scholars and completed the school education in English $(82.1 \%)$ as a medium of instruction. Sizeable portion

of the respondents are completed their course work (36.4\%) examination and in the review collection stage (24.3\%) for their research in the Anna University and its affiliated institutes. Descriptive statistics reveals that mean age of the research scholars participated in the survey is 27.84 years with the standard deviation of 4.945 and age ranging from 22 years to 49 years.

\section{B. Exploratory Factor Analysis - Social Skills}

Social skills are the ability to identify, assess and control the emotions of oneself, of others and the groups in order to get social support and respond from others, as it enables the research scholars to develop good interpersonal relationship. It helps in managing relationships to move people in the desired direction. The social skill is very important for the effective academic achievement of the scholars which depends on the capabilities and aspiration of the individual. There are four factors which are identified as the relevant aspect of social skill of the research scholars.

Table 2: Exploratory Factor Analysis - Social Skills Variables

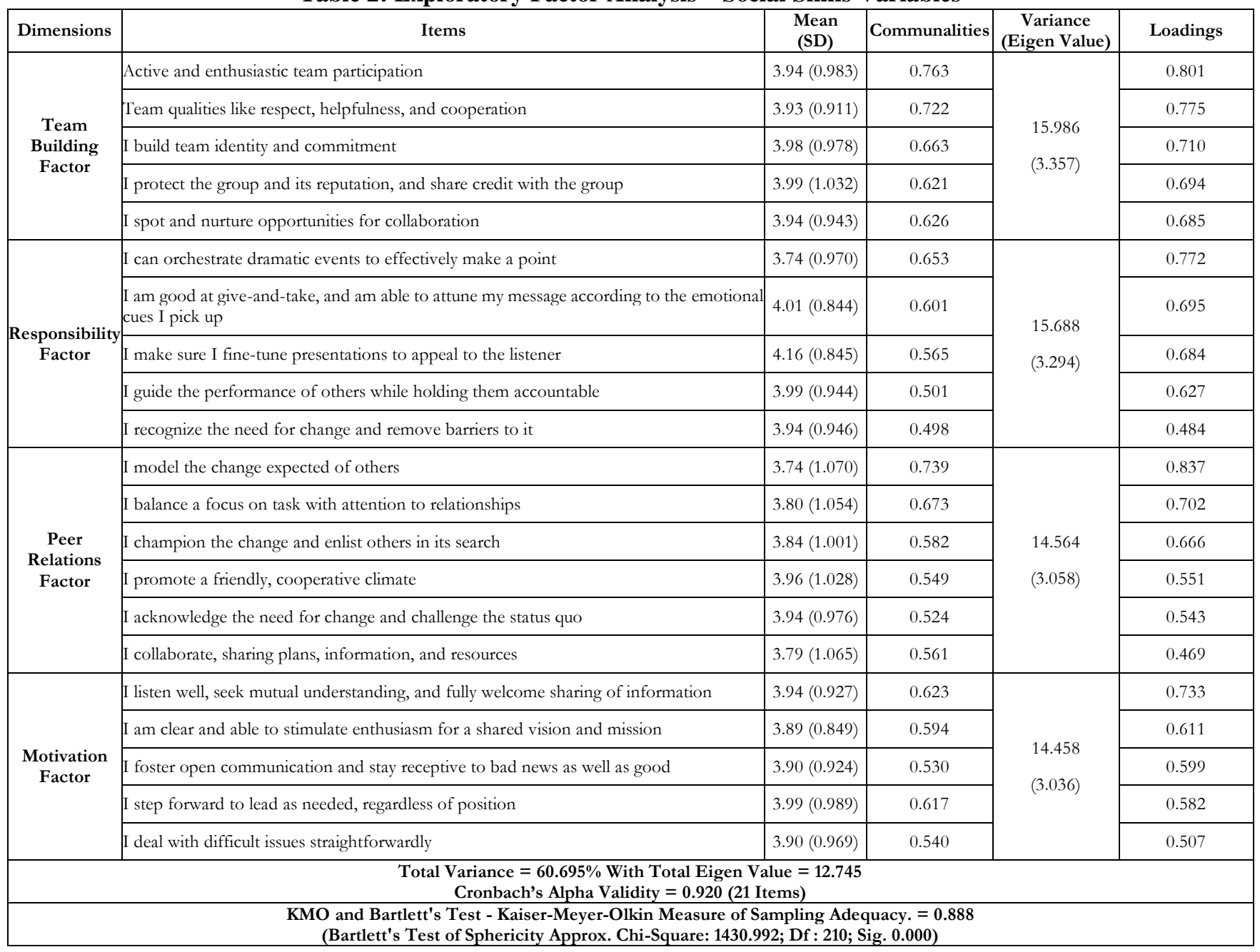

Table 2 reveals that KMO measure of sampling adequacy is 0.888 , Bartlett's Test of Sphericity with approximate chi square value 1430.992 , $D f=210$ and $p=0.000$ are statistically significant at 5 percent level. The minimum criteria accepted index is over 0.6 this showed that the sample size was enough for the study. KMO - Test of suitability of

factor analysis varies between 0 and 1 , and value closer to 1 are better and therefore suitable for exploratory factor analysis and that the 21 items 


\section{Social Skills Acquisition Among Engineering and Management Research Scholars}

have exhibited the communalities variances from 0.498 to 0.763 .

This implies that the range of variations defined "between" 49 percent to 76 percent, which is statistically significant to go ahead for the meaningful data reduction process. In addition, the 21 variables are reduced into 4 predominated groups. It is found that the variable exhibits the total variance $60.695 \%$ with total Eigen value 12.745 indicates also go ahead for the meaningful data reduction process.

The most dominant factor is factor 1 with the explained variance of 15.986 with Eigen value of 3.357 and it has five variables related to the social skills of research scholars and it has been labelled as "Team Building Factor". This team building activity is very important in any team-building process, as it helps to build the team identity and commitment in order to demonstrate the team behavior in different aspects and to attain the high performance. This activity should be integrated in any team-building effort, as they allow to spot the opportunities for the collaboration. It helps to solve the problems through the group decisions.

Second dominant factor is factor 2 with the explained variance of 15.688 with Eigen value of 3.294 and it has five variables related to the social skills and it has been labelled as "Responsibility Factor". The scholars must recognize the need for change and remove the barriers through the performance which makes the individual to feel accountable over the action. The level of responsibility depends on emotional cues of the interested groups which relate to the social responsibility and sustainability to make an effective delivery of the emotions.

Factor 3 with the explained variance of 14.564 with Eigen value of 3.058 and it has six variables related to the social skills of research scholars and it has been labelled as "Peer Relations Factor".It is an important factor as it identifies how the individual get along with others. The influence of socialization helps to examine and interact with one another in the matter of opportunities. It helps to create a balance in the relationship though an effective focus on the job.

Factor 4 with the explained variance of 14.458 with Eigen value of 3.036 and it has five variables related to the social skills of research and it has been labelled as "Motivation Factor".It is important element of emotional intelligence which helps for the improvement of the academic performance through the mutual understanding and sharing of the information. It involves the power of being driven to deal with the problems in order to achieve the desired goals. In the context of this article, motivation encompasses the emotional intelligence that guide or facilitate to the research goals of the scholars.

Thus, four independent, meaningful and manageable factors have been extracted out of 21 social skills variables of which the team building factor is the most dominant factor followed by responsibility factor, peer relations factor and motivation factor in their order of dominance.

\section{The Independent Sample t-test}

The independent sample t-test has been conducted to compare mean difference between demographic segmentation with respect to Gender, Marital Status, nature of research with the emotional intelligence dimensions towards research scholars.

H0: Hypothesis: There is no significant difference between Gender, Marital Status, nature of research with the social skills among research scholars.

Table 3: Independent Sample t test for Comparing demographic variables of Gender, Marital Status, nature of research with the social skills among research scholars

\begin{tabular}{|l|c|c|c|}
\hline Dimension & $\begin{array}{c}\text { Gender } \\
\text { t-Value } \\
\text { (P-Value) }\end{array}$ & $\begin{array}{c}\text { Marital } \\
\text { Status } \\
\text { t-Value } \\
\text { (P-Value) }\end{array}$ & $\begin{array}{c}\text { Nature of } \\
\text { Researcher } \\
\text { t-Value } \\
\text { (P-Value) }\end{array}$ \\
\hline \multirow{2}{*}{ Social - Skills } & -1.276 & $\mathbf{2 . 2 5 2}$ & 0.428 \\
& $(0.204)$ & $\mathbf{( 0 . 0 2 6 ) * *}$ & $(0.669)$ \\
& $-2.712 \#$ & $\mathbf{5 . 2 6 5 \#}$ & $1.026 \#$ \\
\hline
\end{tabular}

\# Denotes: Mean Differences; ** Denotes: $5 \%$ Level of Significance

The above table reveals that there is a significant mean difference between marital status and social skills ( $\mathrm{t}$-value $=$ 2.252; Mean Difference $=5.265 ; \mathrm{p}<0.026$ ) at $5 \%$ level of significance. Hence, the null hypothesis was rejected and alternative hypothesis accepted.

\section{ONE-WAY ANOVA}

One-way ANOVA test was performed to know the significant mean difference between the group of demographic characteristics of medium of school education, course work completion and research stage of the research scholars with respect to the social skills. The results of one-way ANOVA were discussed below.

H0: Hypothesis: There is no significant difference between demographic and educational profiles of medium of school education, course work completion and research stage of the research scholars with respect to the social skills.

Table 4: One-Way ANOVA for significance of difference with respect to educational profiles of the research scholars on social skills

\begin{tabular}{|l|c|c|c|}
\hline \multicolumn{1}{|c|}{ Dimension } & $\begin{array}{c}\text { Medium of } \\
\text { School } \\
\text { Education } \\
\text { F-Value } \\
(\mathbf{P}-\text { Value })\end{array}$ & $\begin{array}{c}\text { Course Work } \\
\text { Completion } \\
\text { F-Value } \\
(\mathbf{P}-\text { Value })\end{array}$ & $\begin{array}{c}\text { Research } \\
\text { Stage } \\
\text { F-Value } \\
\text { (P-Value) }\end{array}$ \\
\hline Social Skills & $\begin{array}{c}4.210 \\
(\mathbf{0 . 0 1 7}) * *\end{array}$ & $\begin{array}{c}4.260 \\
(\mathbf{0 . 0 1 6}) * *\end{array}$ & $\begin{array}{c}3.905 \\
(\mathbf{0 . 0 0 1})^{* *}\end{array}$ \\
\hline ** Denotes: 5\% Level of Significance & \multicolumn{3}{|l}{} \\
\hline
\end{tabular}

Table 4 shows that there is a significant difference between medium of instruction, course work completion and research stage of research scholars with respect to social skills at $5 \%$ level of significance. Hence, the null hypothesis was rejected and alternative hypothesis accepted.

\section{MAJOR FINDINGS OF THE STUDY}

- Majority of the respondents are males (52.9\%), unmarried $(72.1 \%)$, non-stipendiary $(72.9 \%)$ research 
scholars and completed the school education in English $(82.1 \%)$ as a medium of instruction. Sizeable portion of the respondents are completed their course work (36.4\%) examination and in the review collection stage (24.3\%) for their research in the Anna University.

- The mean age of the research scholars participated in the survey is 27.84 years with the standard deviation of 4.945 and age ranging from 22 years to 49 years

- Four independent, meaningful and manageable factors have been extracted out of 21 social skills variables of which the team building factor is the most dominant factor followed by responsibility factor, peer relations factor and motivation factor in their order of dominance.

- There is a significant mean difference between marital status and social skills ( $\mathrm{t}$-value $=2.252$; Mean Difference $=5.265 ; \mathrm{p}<0.026)$ at $5 \%$ level of significance.

- There is a significant difference between medium of instruction, course work completion and research stage of research scholars with respect to social skills at $5 \%$ level of significance.

\section{IMPLICATIONS AND CONCLUSION}

The following suggestions were proposed for different stakeholders, as a result of conclusion drawn from the study. Research scholars should be more versatile, dynamic and concentrate on their research work continuously in order to finish the research within the stipulated research period. Research scholars should develop and focus on their vision to utilize all the opportunities that they come across in their research and academic life to overcome the fear. Acquisition of social skills is the major component for the betterment in their level of emotional intelligence to tackle in the all circumstances. Research supervisors should encourage their research scholars to develop the social skills through the research scholar active participation in the various national and international conferences outside the home town. This will help the research scholar to overcome the fear of presenting the research work. Research supervisors periodically monitor the progress of the research scholars effectively in order to complete the research within the stipulated research period.

This primary survey was conducted with a primary objective to understand the social skills acquisition of Research Scholar in the Anna University. This empirical evidence proves that social skills acquisition was significantly grouped into four major components namely, the team building factor is the most dominant factor followed by responsibility factor, peer relations factor and motivation factor. Further, the research proves that research scholars participated in the survey have higher perception towards all the four components of social skills acquisition. The researchers are suggested to develop and enrich their social skills and self-competence in order to complete their research within the stipulated time.

\section{LIMITATIONS AND SCOPE OF FUTURE DIRECTIONS}

The primary data was collected only from research scholars of Anna University, Chennai. Therefore, a broad generalization of the findings may not be valid for the other state and central universities because of the difference in social and cultural factors in different parts of our country. The study pertains only to the social skills acquisition of research scholars. The acquisition of skills is very difficult to measure since they are mostly subjective and are based on self-report of research scholars. There is a possibility of hidden information due to their fear of exposure or embarrassment or to protect their privacy. A study on researchers' behavior cannot be given an enduring and long-lasting finding over a period of time. Behavioral patterns and acquisition of social skills are likely to change with socio economic and cultural changes. Further, it can be further extended to find out the other dimensions such as emotional intelligence, research integration, research skills acquisition and employment decision making of research scholars.

"Teachers should be the best minds in the country Sarvapalli Shri. S. Radhakrishnan, Former President of India".

\section{REFERENCES}

1. Agarwal, P. (2006). Higher education in India: The need for change (No 180). Working paper.

2. Andrews, J., \& Higson, H. (2008). Graduate employability, 'soft skills' versus 'hard' business knowledge: A European study. Higher Education in Europe, 33(4), 411-422.

3. Ball, S. J. (2017). The Education Debate. Policy Press.

4. Biggs, J. (2001). The reflective institution: Assuring and enhancing the quality of teaching and learning. Higher Education, 41(3), 221-238.

5. Boud, D., \& Falchikov, N. (1989). Quantitative studies of student self-assessment in higher education: A critical analysis of findings. Higher Education, 18(5), 529-549.

6. Charles Olan Skipper \& Stefanie Brandenburg (2013) Emotional intelligence and academic performance of engineering students, Engineering Project Organization Journal, 3:1, 13-21, DOI: 10.1080/21573727.2012.738669

7. Fabio, A. D., \& Kenny, M. E. (2012). Emotional intelligence and perceived social support among Italian high school students. Journal of Career Development, 39(5), 461-475.

8. Garet, M. S., Porter, A. C., Desimone, L., Birman, B. F., \& Yoon, K. S (2001). What makes professional development effective? Results from a national sample of teachers. American educational research journal, 38(4), 915-945.

9. Jayaram, N. (2004). Higher Education in India. Asian universities: Historical perspectives and contemporary challenges, 85 .

10. Kumar, S., \& Dash, M. K. (2011). Management education in India: trends, issues and implications. Research Journal of International Studies, 18(1), 16-26.

11. Madhavan, M., \& Kitratporn, P. (2016). Measuring the Relationship between Emotional Intelligence and Academic Achievement of Business Students. Available at SSRN: https://ssrn.com/abstract=2779015 or http://dx.doi.org/10.2139/ssrn.2779015

12. Muralidharan, K. (2013, April). Priorities for primary education policy in India's 12th five-year plan. In India Policy Forum (Vol. 9, No. 1, pp. 1-61) National Council of Applied Economic Research.

13. National Research Council. (1996). National science education standards National Academies Press.

14. Poulou, M. S. (2017). Students' Emotional and Behavioral Difficulties: The Role of Teachers' Social and Emotional Learning and Teacher-Studen Relationships. International Journal of Emotional Education, 9(2), 72-89.

15. Poulou, M. S., Bassett, H. H., \& Denham, S. A. (2018). Teachers' Perceptions of Emotional Intelligence and Social-Emotional Learning: Students' Emotional and Behavioral Difficulties in U.S. and Greek Preschool Classrooms. Journal of Research in Childhood Education, 32(3), 363-377. doi:10.1080/02568543.2018.1464980

16. Singh, J. D. (2011). Higher education in India-Issues, challenges and suggestions. Higher Education, 93-103. 


\section{Social Skills Acquisition Among Engineering and Management Research Scholars}

17. Trigwell, K., \& Prosser, M. (1991). Improving the quality of student learning: the influence of learning context and student approaches to learning on learning outcomes. Higher Education, 22(3), 251-266.

18. Trowler, P. (2008). Cultures and change in higher education: Theories and practices. Macmillan International Higher Education.

19. Zandi, M. (2012). The role of emotional intelligence in French language learning and academic success of the male students. Procedia-Social and Behavioral Sciences, 46, 5714-5717.

20. Zandi, M. (2012). The role of emotional intelligence in French language learning and academic success of the female students. Procedia-Social and Behavioral Sciences, 46, 4986-4989.

21. Zusman, A. (2005). Challenges facing higher education in the twenty-first century. American higher education in the twenty-first century: Social, political, and economic challenges, 2, 115-160.

\section{AUTHORS PROFILE}

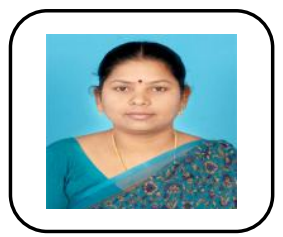

Dr. S. Jayalakshmi, was qualified with B.Com. M.B.A., M.Phil., \& Ph.D.,.and currently working as Assistant Professor, in Department of Commerce at Chellammal Women's College. She has completed my 19 years of teaching experience (Both UG, PG \& 7 years research). She has produced 20 M.Phil's, and guiding 6 Ph.D. scholars at present. She has published many national and International Journal and many papers presented in both national and International conference. I received "senior educator \& scholar award" in the year 2015 .

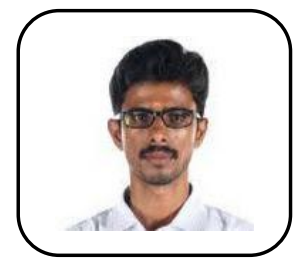

Dr. P. Balaji, Assistant Professor in Post Graduate and Research Department of Commerce, Guru Nanak College (Autonomous), Chennai. He has received Under-Graduation, Post-Graduation, Master of Philosophy and Doctor of Philosophy in Commerce from University of Madras, Chennai. $\mathrm{He}$ is the Lime Member of Indian Commerce Association, Indian Accounting Association and Indian Finance Association. He has posses four years of research experience and one year teaching experience in the realm of commerce. He has cleared UGC NET and Tamil Nadu SET in the subject of Commerce. He was specialized in teachings related to Banking, Marketing and Human Resource Management and has research interest in the field of Banking Technology, Marketing Research and Human Resource Development. He has contributed many empirical research articles to various eminent national and international level journals in the field of commerce and management indexed in SCOPUS/UGC CARE listed Journals and also actively participating in various national and international conferences. $\mathrm{He}$ has received three best paper awards in various international and national conferences. He is the recipient of UGC Non-NET fellowship from Department of Commerce, University of Madras, Chennai. He was awarded University Research Fellowship from the Department of Commerce, University of Madras, Chennai and received Doctoral Research Fellowship from Institute of Public Enterprise, Hyderabad in collaboration with Indian Council of Social Science Research (ICSSR) for the doctoral thesis awarded from Department of Commerce, School of Business and Management Studies, University of Madras, Chennai. 